\title{
A dinâmica da rede sob a perspectiva social: $O$ caso da Vila de Paranapiacaba
}

\author{
Marcius Fabius Carvalho ${ }^{i}$ \\ Ernesto Michelangelo Giglio ${ }^{i i}$
}

Universidade Paulista (Brasil)

\begin{abstract}
Resumo: O trabalho analisa a dinâmica das redes de empresas nas dimensões econômicas, técnicas e sociais, mostrando que as relações mudam conforme os objetivos econômicos e políticos. Afirma-se que as redes se transformam ao longo do tempo surgindo diferentes estruturas e formas de relações, com variados graus de flexibilidade, inovação e cultura, em contrapartida à visão de que elas nascem e morrem. O trabalho analisa a evolução do ambiente da Vila de Paranapiacaba, no Estado de São Paulo, desde sua criação até a situação atual, utilizando documentos, acompanhamento e entrevistas e conclui que Paranapiacaba passou por quatro diferentes configurações de redes. $\mathrm{Na}$ atualidade predomina o objetivo de turismo, que regula as relações sociais e de negócios. Os dados sustentam a afirmativa da evolução das redes.
\end{abstract}

Palavras-chave: Redes; Desenvolvimento local; Evolução de redes; Modelos em redes; Objetivos econômicos e redes.

Title: The dynamics of the network from a social perspective: The case of Vila Paranapiacaba

Abstract: The study analyzes the dynamic networks in the economic, technical and social dimensions, that indicates the change of relations with the economic and political objectives. It is stated that the networks evolve over time, emerging new structures and forms of relationships, with various degrees of flexibility, innovation and culture, as opposed to a view that a network born and die. The study examines the evolution of the Village of Paranapiacaba environment, in São Paulo, Brazil, since its creation to the current state, through documents, observation and interviews and conclude that the Village went through four different networks configurations. Now the predominance is tourism objective, which regulates the social and business relations. The results support the affirmative of networks evolution.

Keywords: Networks; Local development; Networks evolution; Networks models; Economics objectives and networks.

i Redes de Negócios e Cadeias de Suprimentos - Programa de Mestrado em Administração UNIP- Universidade Paulista e Pesquisador do Centro de Tecnologia da Informação- CTI em São Paulo- Brasil. Email: marcius. carvalho@pesquisador.cnpq.br

ii Professor da disciplina de Redes de Negócios do Programa de Mestrado em Administração da UNIP- Universidade Paulista em São Paulo- Brasil. Email: ernesto_giglio@yahoo.com.br 


\section{Introdução}

Concentrações geográficas de empresas e instituições interconectadas, em um campo particular, podem criar vantagem competitiva (Porter, 1998). Estas concentrações ocorrem por fatores diversos e no caso de grandes empresas, elas se dirigem à determinada região de um país à busca de incentivos fiscais e outras facilidades como mão de obra mais barata, maior número de horas trabalhadas e, no sentido de transferirem investimentos e incertezas para seus parceiros, estabelecem formas de gestão e de produção que contribuem para a convergência de empresas fornecedoras para a mesma região. Cria-se uma competência local como é o caso dos consórcios e condomínios, para montagem modular, que proliferam nas áreas automotivas, de equipamentos eletrônicos, de vestuário, incentivando o desenvolvimento de habilidades locais.

A habilidade de uma região em desenvolver-se em determinado ramo de negócios pode ocorrer também por questões históricas, principalmente quando apoiadas pela Tecnologia de Informação, que aparece como ferramenta facilitadora de parcerias, encurtando distâncias, promovendo a visibilidade do produto e gerando o mesmo efeito das habilidades incentivadas.

Identificados os fatores locais como fundamentais para o acompanhamento da dinâmica torna-se importante estudá-los e entendê-los nas suas diferentes formas. Embora os conceitos e posições apresentadas a seguir possam ser adaptados para qualquer dos agrupamentos acima, ou seja, para os induzidos por grandes empresas ou os históricos, este texto toma os arranjos produtivos locais como elemento de análise, para desenvolvimento de conceitos a serem aplicados em um ambiente.

Assim, o objetivo deste trabalho é analisar a dinâmica das redes de empresas nas dimensões econômicas, técnicas e sociais, a partir do estudo de um caso, afirmando e mostrando que as relações mudam com os rumos econômicos e políticos em que a rede está inserida. Esta afirmativa de transformação das redes é uma contraposição a uma visão de que as redes nascem e morrem, oriunda principalmente da literatura americana, mais interessada nos contratos temporais de redes, tais como joint-ventures e alianças (Grandori, Soda, 1995). Nossa afirmativa orientadora é que ocorrem evoluções na rede as quais podem ser adequadamente analisadas se usarmos os fatores de relacionamentos entre os atores, os recursos, os objetivos e as atividades deles decorrentes. A proposta apóia-se em modelos já existentes, tais como o ARA - Actors, Resources, Activities (Hakanson, Snehota, 1995), porém voltado a serviços e refazen- do a conjunção dos fatores.

A partir desta proposta analisamos um caso, mostrando que no espaço turístico esta evolução é motivada por fatores culturais, históricos e econômicos.

$\mathrm{O}$ artigo se justifica uma vez que há uma crescente discussão e busca de aplicação dos conceitos na gerência de redes, mais acentuadamente nos negócios de serviços, como turismo e saúde. Antes da metodologia, apresentamos alguns conceitos básicos sobre redes que apóiam a proposta.

\section{Arranjos produtivos}

Arranjos produtivos se constituem em um tipo particular de aglomerado, formado por pequenas e médias empresas, com as mesmas habilidades, ou habilidades complementares; agrupadas em torno de uma profissão ou de um negócio, onde se destaca o papel desempenhado pelos relacionamentos formais e informais entre empresas locais e demais instituições envolvidas. Os atores de uma determinada concentração compartilham uma cultura comum e interagem, como um grupo, com o ambiente sociocultural. Quando não há significativa articulação entre os atores, além de pouca ou nenhuma inovação, as concentrações são chamadas de arranjos produtivos locais. Quando o conjunto de atores econômicos, políticos e sociais, de uma concentração geográfica, desenvolve atividades econômicas correlatas que apresentam vínculos expressivos de produção, iteração, cooperação e aprendizagem, passa a se chamar sistemas produtivos locais (Lastres, Cassiolato, 2005).

$\mathrm{Na}$ visão do Serviço Brasileiro de Apoio a Pequena e Micro Empresa - Sebrae, os sistemas produtivos locais (clusters) são concentrações geográficas de empresas e instituições conectadas em um campo particular (Caporali, Volker, 2004). Para Porter (1998) cluster é uma concentração geográfica de empresas conectadas e instituições em um determinado campo. Inclui, por exemplo, fornecedores especializados de componentes ou máquinas, serviços e fornecedores de infra-estrutura adequada. Abaixo do canal estão os consumidores e na lateral as empresas complementares e empresas dos setores afins. Podem também participar as instituições do governo, universidade, agências e suporte técnico. Todos compartilham interesses comuns e trocam recursos à busca destes interesses compartilhados, reconhecendo a cooperação como o melhor caminho para atingir estes objetivos. Desenvolve-se uma estrutura organizacional onde cada componente é importante para a competitividade individual dos demais. Nesse modelo, identificase, com freqüência, uma liderança local que coordena as ações do arranjo. 
Para o Sebrae (2003) estas ações de coordenação serão exercidas pela governança local que agrega os diferentes modos de liderança, coordenação, intervenção, participação e negociação dos conflitos nos processos decisórios locais, assim como no processo de geração, disseminação e uso de conhecimentos. Para isso deve envolver diferentes agentes das diversas atividades produtivas formando uma rede entre governos, empresas, cidadãos, trabalhadores, associações e organizações não governamentais entre outros.

A governança pode se apresentar sob as formas de hierarquia e de rede, sendo a primeira observada quando é claramente exercida por um único ator que coordena as relações econômicas, tecnológicas e políticas no âmbito local e ocorre normalmente quando, por exemplo, o arranjo produtivo local é liderado por uma grande empresa integradora. Já a governança, sob a forma de rede, é caracterizada pela intensidade de relações entre um amplo número de agentes, onde nenhum deles é dominante (Sebrae, 2003). Este último tipo de governança é o encontrado em um espaço turístico. Uma das características do agrupamento neste caso é a maior interdependência entre os atores, incluindo relações sociais, com valores compartilhados. Outros fatores tais como confiança, transparência e comprometimento são importantes guias das relações entre os atores (Larson, 1992; Castells, 2000). Estes fatores, operando em conjunto, fazem surgir uma característica coletiva que é mais do que a soma das partes, nascendo uma entropia que vai movimentando essas mesmas relações cada vez de forma mais independente dos atores (Maturana, Varela, 2001). Nessa situação, é possível afirmar que existe uma rede.

\section{Conceitos de rede}

Vale (2004), Giglio e Kwasnicka (2005), em artigos que realizaram uma busca bibliográfica, apontam dois enfoques para os conceitos de redes de negócios. O primeiro enfoque parte da consideração que a existência de uma rede social influencia a criação de arranjos sociais específicos, entre eles, as redes de negócios. A partir daí define-se redes de negócio como uma ligação especial, derivada das redes sociais, as quais todos fazemos parte.

Por outro lado, advindo de escolas de raciocínio econômico, define-se a rede de negócios como um arranjo planejado das empresas, buscando uma vantagem que isoladamente torna-se mais difícil de alcançar. Certamente este enfoque é mais adequado para os condomínios e consócios constituídos por grandes empresas. Este artigo utiliza o conceito de redes sociais para o es- tudo da dinâmica em espaços turísticos.

As estruturas sociais são organizadas em torno de relações de produção, consumo, poder e experiência, nas configurações espaços-temporais que constituem a cultura (Castells, 2000). Surge uma nova estrutura social quando existem transformações em alguma, ou em várias relações que, em conjunto, conduzem a mudanças da cultura. Como exemplo, no fim do século XIX havia uma cultura em que a produção era artesanal, voltada a poucos produtos para um mercado regional e realizada por pequenas empresas controladas, na maioria das vezes, por uma única pessoa, que se incumbia de todas as tarefas, principalmente as tarefas administrativas. Esta forma de cultura foi substituída, no início do século XX, pela produção em massa que buscava altos índices de produtividade e reduções significativas de custos, forma que impulsionou a verticalização das empresas e a concentração dos recursos produtivos em poucos proprietários, formando uma nova cultura, por exemplo, a das grandes marcas. O paradigma tecnológico desta era se baseava na produção e distribuição de energia, fator fundamental e elemento impulsionador da então nova cultura.

A tecnologia, que é o uso do conhecimento científico para a especificação de formas de fazer coisas de maneira reproduzível, constitui-se a base para a evolução da relação de produção, de consumo, de experiência, de poder e, portanto, cultura das organizações. A tecnologia é o ingrediente fundamental para a ação humana - ação que em seu fim produz e modifica a estrutura social.

A partir do meio do século XX, com o advento dos computadores, deu-se início ao que posteriormente veio a se chamar de a era da informação, que pode ser definida como o período histórico onde a sociedade desempenha suas atividades por meio de um paradigma construído sobre as tecnologias de informação e comunicação (Castells, 2000). Esta tecnologia, constituída de um conjunto de ferramentas que proporciona nova cultura, impulsionou a formação de redes de empresas por permitir agilidade no conhecimento das necessidades do cliente e a inclusão do consumidor na etapa de produção. Ao mesmo tempo, e também apoiado pelas redes de informação, houve um movimento no sentido das empresas se voltarem para sua competência central buscando recursos complementares em parceiros externos (Grandori, Soda, 2006). A era da informação facilita a existência da interdependência entre atores e a integração de recursos em uma rede, no sentido de aumentar o valor do produto para o cliente final. Vê-se o mercado como redes interconectadas de trocas de relacionamentos o que impulsiona as pesquisas para analisar e descrever as características destas redes (Mouzas et al., 2007). 
O ponto básico de nossa argumentação é que sendo uma rede social definida como um conjunto de nós (pessoas, organizações) interligadas por um conjunto de relações (de confiança, de transferência de fundos, ...) ela é dinâmica e evolui no espaço e no tempo criando cultura como um sistema de valores e de comportamentos resultantes de compartilhamento de conteúdos e significados. Esta afirmativa é oposta aos conceitos de redes econômicas, que supõem um ciclo de vida, ou seja, as redes terminam quando seus objetivos econômicos não são mais alcançados.

\section{A representação por redes}

Admitindo uma rede social como um conjunto específico de relações (ligações) entre um grupo definido de pessoas e/ou organizações, pode-se representá-la, de forma esquemática, como um conjunto de nós e arcos chamado grafo, conforme a Figura 1. Por definição uma rede social não tem um centro e trabalha em lógica binária de inclusão/exclusão. Assim, tudo que está na rede é necessário para a existência da rede. Se um nó (pessoa ou organização) deixa de exercer uma função útil à rede ele deve sair da rede e esta deve se rearranjar. Pode haver um nó mais importante que outro, mas todos necessitam uns dos outros desde que estejam na rede (Tichy, Tushman, Fombrun, 1979). Um nó se torna mais importante na medida em que absorve mais informação e processa-a com maior eficiência. Assim, a relevância e o peso de um nó é conseqüência da habilidade de criar relacionamentos na rede e de sua capacidade de absorver e tratar informações. É possível desenvolver medidas para avaliar cada um destes fatores com relação aos nós e ligações (Borgatti, Everett, 2006).

Os arcos de uma rede social representam os relacionamentos entre nós e a não existência de um arco, por exemplo (entre o nó i e o nó n), significa que não há

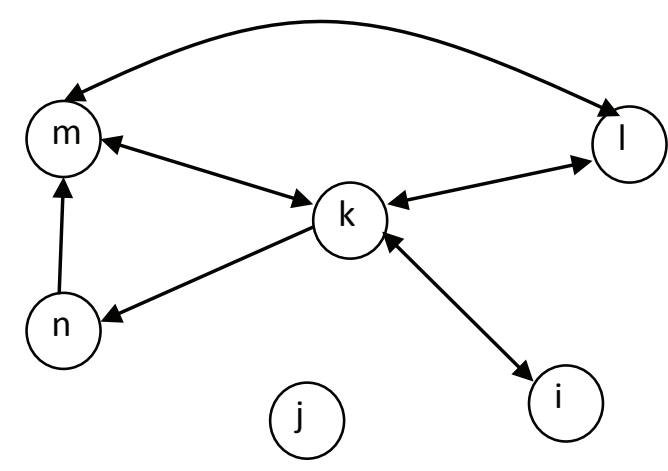

Figura 1. A rede de relacionamentos que representa a rede, com os nós e os arcos. Fonte: os autores, 2009 relacionamento direto entre estes nós. Será chamado de buraco estrutural quando estes nós estiverem conectados somente por meio do nó focal que para o exemplo dado é o nó " $\mathrm{k}$ " (i encontra $\mathrm{m}$ passando por k). Ainda, no exemplo da Figura 1, o nó “j” não apresenta relacionamento com a rede e, portanto, está fora dela. Há várias medidas associadas a uma rede como a densidade, conectividade, encontrabilidade, a centralidade, o número de clusters e outras, que serão analisadas à frente.

\section{Metodologia para análise de redes}

Considerando o objetivo de análise de mudanças da rede no tempo e a característica qualitativa das variáveis, isto é, as relações entre os fatores estruturantes, o trabalho segue uma metodologia qualitativa, com descrição dos fenômenos; análise das possíveis conjunções e uma discussão sobre a sustentação da afirmativa orientadora. A abordagem qualitativa exploratória tem sido defendida no estudo de redes, em artigos de Larson (1992) e Halinen e Tahtinen (2002), uma vez que o campo se encontra numa situação de desenvolvimento científico inicial, existindo paradigmas com princípios diferentes e até opostos. O estudo de caso aplicado a redes também foi defendido por Halinen e Tornroos (2005), a partir da crença na especificidade de cada rede.

Tendo analisado a bibliografia existente e refletido sobre os conceitos de redes, tomam-se como elementos estruturantes os atores (pessoas ou organizações), interligados por relações sociais; os recursos e os objetivos, que ordenam os processos, numa visão sistêmica. O sistemismo considera que os sentidos das relações podem ser bidirecionais, num raciocínio de realimentação. Conforme Morin (1991) o raciocínio sistêmico é adequado para fenômenos complexos, sem a evidência de relações causais claramente definidas. A tecnologia torna-se também um importante elemento estruturante à medida que possibilita novas formas de relações sociais e desenvolve os objetivos conduzindo a dinâmica da rede.

A Figura 2 mostra o desenho das interfaces entre as variáveis, que servirá de modelo para a análise da dinâmica de um objeto de estudo pelos conceitos de redes sociais. No centro estão os atores, que constroem seus relacionamentos sociais de produção, de consumo, de poder, de experiência (Castells, 1999) conforme suas posições na rede com relação aos objetivos, aos recursos e uso da tecnologia.

A análise da dinâmica nas relações dos elementos da Figura 2 inclui dois aspectos básicos: a análise de uma configuração em determinado tempo e a evolução da rede no tempo. $\mathrm{O}$ desenho também abarca os aspectos 


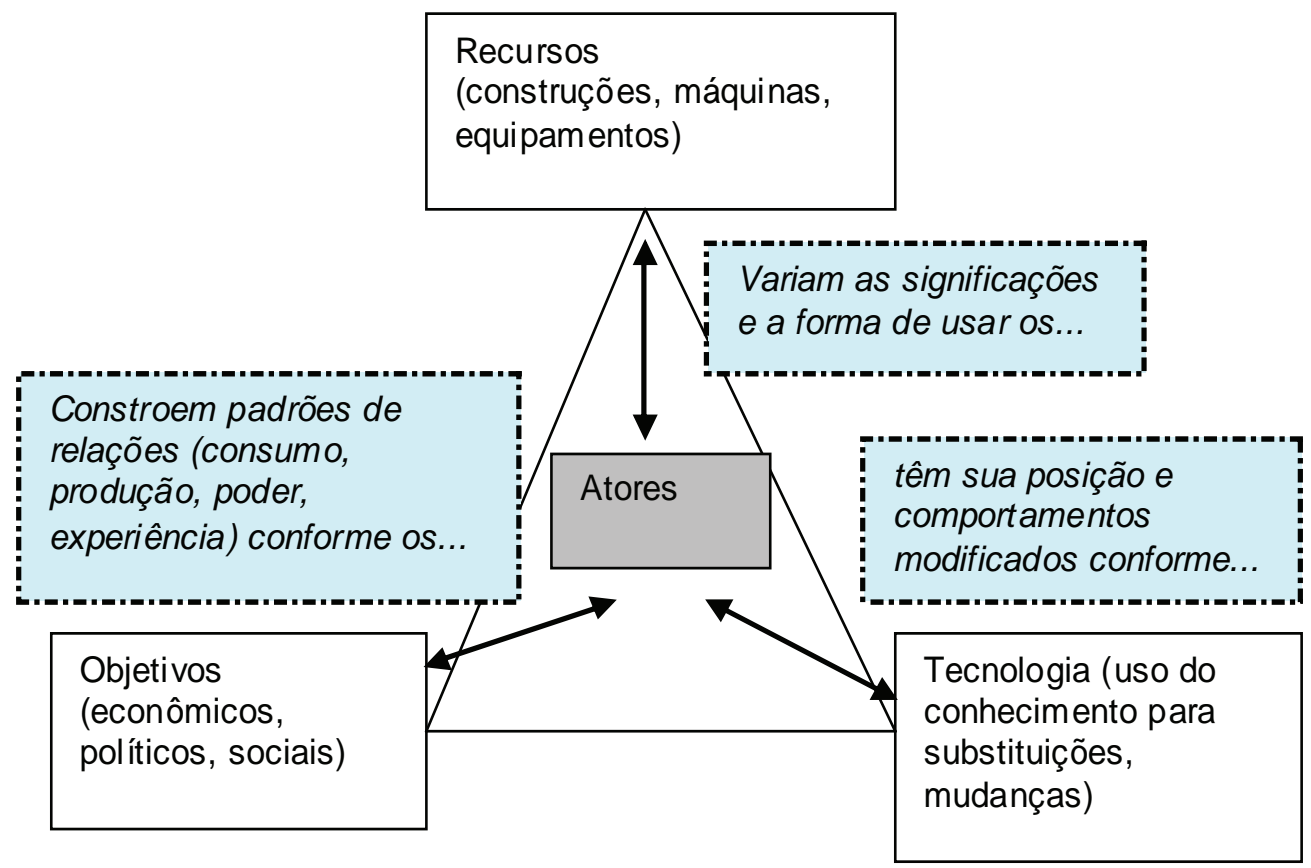

Figura 2. O modelo de análise da dinâmica de uma determinada rede social. Fonte: construção dos autores, 2009

básicos de uma rede, na perspectiva dos conceitos de redes sociais, quais sejam:

1. A Dinâmica

2. O Conteúdo Transacional

3. A Natureza do relacionamento

4. As Características estruturais

\section{Dinâmica}

Como um elemento do sistema social, toda rede evolui e se transforma ao longo do tempo. Contudo, segundo Gemser, Leenders e Wijnberg (1996), há poucos estudos que focam em como e por quê as relações interorganizacionais de produção, consumo, poder e experiência mudam ao longo do tempo. Alguns estudos, como os de Castells (1999), analisam os grandes movimentos sociais, considerando somente aqueles internos a uma rede específica. Existem clusters que também apresentam dinâmicas, evoluindo com o tempo e modificando a rede. A dinâmica da composição da rede causa movimentos que podem modificar as relações de produção, consumo, poder e experiência, conduzindo a uma nova cultura na rede pelas transformações em algumas ou em várias das relações entre os atores (Castells, 2000). Existe aqui, portanto, uma visão sistêmica de interdependência, onde antecedentes e conseqüentes mudam de posição e a explicação para mudança pode ser encontrada dentro do próprio sistema.

\section{Conteúdo transacional}

Tichy, Tushman e Fombrun (1979) colocam que o conteúdo transacional pode se expressar de quatro formas:

A. Expressão de afeto ou de amizade que pode ocorrer entre setores (membros) da rede.

B. Troca de influência e poder

C. Troca de informação

D. Troca de produto ou serviço

Segundo Tichy, Tushman e Fombrun (1979), uma rede pode tornar-se diferente no seu desenho para cada um dos conteúdos transacionados. Por exemplo, a rede para troca de informação pode estar altamente conectada e descentralizada, enquanto a rede de influência pode ser centralizada e mediada por um único supervisor.

\section{Natureza do relacionamento}

Segundo Tichy, Tushman e Fombrun (1979), o objetivo e a natureza do relacionamento determinam como os elementos da rede interagem e, entre as formas de interação, as principais características são:

a) Intensidade: Mede o grau que os indivíduos honram as obrigações, ou se comprometem com custos, ou se envolvem em contatos durante uma unidade de tempo.

b) Reciprocidade: Mede o equilíbrio com que se dá uma relação. Em uma relação de alta reciprocidade a intensidade com que os elementos envolvidos se relacio- 
nam tem a mesma intensidade em ambos sentidos.

c) Visibilidade das expectativas: Mede o grau com que os indivíduos entendem como deve ser o comportamento apropriado das relações bilaterais.

d) Multiplicidade: Um indivíduo pode ter múltiplos papéis tais como trabalhador, marido, membro de uma comunidade, e membro de um grupo. A multiplicidade identifica o grau que um par é ligado em múltiplas tarefas. Quanto mais tarefas ligam um indivíduo a outro mais forte é a ligação.

\section{Carac terísticas estruturais}

Conforme Tichy, Tushman e Fombrun (1979), as características estruturais estão ligadas aos nós, em sua disposição na rede e em como se encontram interligados. Seriam elas:

A. Tamanho: É o número de indivíduos ou elementos pertencentes à rede.

B. Densidade ou conectividade: É o número de ligações na rede. É definido como a razão entre o número de ligações atuais e o número de possíveis ligações.

C. Clusters: É formado por um conjunto de elementos com características semelhantes, e que se agrupam por afinidades. $\mathrm{O}$ número de clusters é determinado pelo número de agrupamentos.

D. Estabilidade: Grau com que o padrão da rede se modifica com o tempo.

E. Abertura: Número de ligações externas de uma unidade social como uma taxa de ligações externas possíveis.

F. Encontrabilidade: O número médio de ligações entre dois nós de uma rede.

G. Centralidade: O grau com que as relações são dirigidas por uma hierarquia formal.

H. Estrela: O indivíduo com o maior número de nominações.

I. Ponte: Um elemento que é membro de múltiplos clusters

Determinadas as variáveis com as quais se analisam as relações sociais que suportam a rede de negócio, é possível passar à descrição e análise do objeto de estudo.

\section{A Vila de Paranapiacaba}

O café, principal produto do Brasil e fator dominante da econômica nacional no Século XIX, fez concentrar esforços que maximizassem sua exportação. Assim, era prioritário estabelecer vias mais adequadas para o escoamento da produção para o Porto de Santos, o que levou à criação, em 1856, da Single Entreprise Ferroviária. Em 1861 começou a construção da ferrovia com toda a tecnologia empregada trazida da Europa e instalou-se um acampamento que chegou a abrigar 5000 homens. A concessão deste trecho da ferrovia foi por 90 anos e vieram ao Brasil executar esse projeto renomados engenheiros ingleses e de outros países da Europa e optou-se pela construção de uma vila para abrigar funcionários, nas proximidades das instalações ferroviárias. A ferrovia foi inaugurada em 1867, com a presença de uma pequena aglomeração urbana na Parte Alta da Vila, formada por casas de pau-a-pique e palha (Prefeitura de Santo André, 2008). A escolha do local foi apenas por uma questão de logística, com a proximidade do porto de Santos.

A partir da Parte Alta houve a ocupação do local hoje correspondente à Vila Velha, pelo acampamento dos operários, que obedeceu à determinação de um eixo principal (Rua Direita), que dava acesso aos depósitos e oficinas. As construções eram de pau-a-pique e pau roliço, cobertas de sapé. As construções da Companhia eram cobertas com folhas de ferro galvanizado ondulado. Basicamente, as características e a feição de acampamento serviam de alojamento à construção da ferrovia (Prefeitura de Santo André, 2008).

A Vila Velha é um conjunto que representa as edificações mais antigas, local que ofereceu infra-estrutura à construção da ferrovia propriamente dita e se destacava na época principalmente em relação à assistência médica através da construção do Hospital do Alto da Serra, um verdadeiro complexo hospitalar constituído de farmácia, necrotério, salas de cirurgia, consultas, internação para o alto escalão, casa infecto-contagiosa, um espaço de isolamento para doenças, além de dependências de funcionários e lavanderia (Prefeitura de Santo André, 2008).

Estes dados históricos permitem visualizar a característica estrutural da rede social ampla, conectada pelo objetivo da construção da ferrovia, com três subsistemas claros: a rede social dos operários, com suas casas e seus códigos de conduta (o que comer, o que beber, etc.); a rede social dos engenheiros e dos técnicos; com sua cultura inglesa e uma terceira rede social médica, uma vez que os acidentes e doenças eram constantes. Esta primeira configuração da rede social pode ser vista na Figura 3. Os atores tinham como visão a ocupação temporária do local, implicando algumas conseqüências, tais como a percepção de que alguns recursos eram descartáveis, tais como as acomodações.

Conforme a ferrovia foi inaugurada e os objetivos comerciais tornaram-se relevantes, surgiu a Vila Nova, ou 


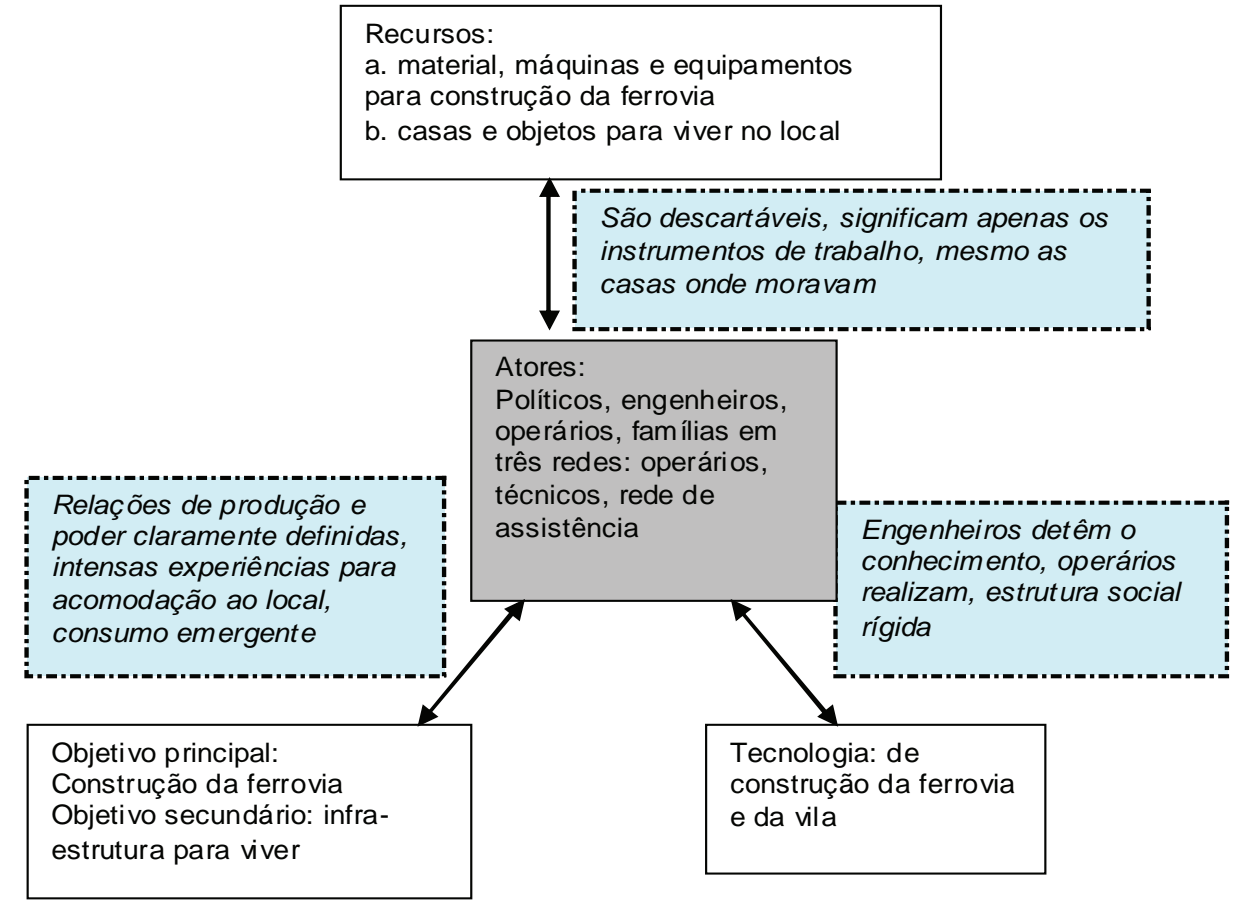

Figura 3. A primeira configuração da rede social de Paranapiacaba. Fonte: construção dos autores, 2009

Vila Martin Smith, juntamente com a construção, em 1901, da segunda obra de subida e descida da serra, estendendo o núcleo original para as áreas vizinhas ao longo do vale. Este trecho de expansão foi planejado e originou um modelo urbano projetado. Este novo conjunto é composto por um modelo de aglomerações disposto hierarquicamente e conforme um arranjo e desenho das edificações, que reforçavam assim o aspecto britânico das construções já existentes, arquitetonicamente diferenciadas pelo material empregado e de tipologias pré-definidas.

A Vila Nova abrigou o que hoje são os grandes atrativos arquitetônicos de Paranapiacaba. Ela foi equipada com a Estação Alto da Serra (destruída por um incêndio em 1981), uma torre com relógio em estilo inglês, que controlava as horas de trabalho e lazer dos funcionários da ferrovia, além de oficinas, pátios de manobra, escritórios, clube, mercado, cinema e campos de golfe, equitação e futebol. Numa das colinas mais elevadas foi erguido o Castelinho, casarão em estilo vitoriano, de onde o superintendente inglês supervisionava os pátios e toda a movimentação dos funcionários da companhia. Em 1907 o vilarejo passou a se chamar Paranapiacaba (do tupi-guarani, "lugar de onde se avista o mar"). Antes disso, era conhecido apenas como Estação do Alto da Serra.
Esta segunda obra, que originou a construção de casas, conforme nossa interpretação, modificou a divisão rígida das sub-redes existentes até então, uma vez que as casas eram de estilo inglês, mas, do que se depreende de documentos da época, eram habitadas tanto por técnicos estrangeiros quanto por técnicos brasileiros. Esta rede tinha no comércio seu objetivo principal e no correto funcionamento da ferrovia o objetivo operacional.

Identifica-se aqui, então, a primeira grande mudança da rede original, conforme se vê na Figura 4. Agora a visão dos atores é de ocupação permanente, implicando em percepções diferentes sobre alguns recursos, tais como moradia e sistemas de saúde.

A concessão da São Paulo Railway Co. terminou em 1946 e não houve acordo entre a companhia e o governo para sua renovação. A Vila de Paranapiacaba e a ferrovia, que passou a se chamar Estrada de Ferro Santos-Jundiaí, ficaram então sob o controle da União. Na década de 50, muitas mudanças de fonte energética ocorreram, como a eletrificação da rede e a utilização do diesel e do óleo cru em substituição ao carvão. As máquinas antigas, os vagões e as locomotivas foram abandonados nos pátios.

Entende-se ser aqui uma nova mudança da rede. Com a mudança do controle da ferrovia e a emergência de novas tecnologias energéticas modifica-se o quadro de mão de obra necessária, mudam os moradores e os processos necessários ao objetivo operacional da ferrovia. O término da concessão da São Paulo Railway Co. é apontado por antigos moradores como o início da decadência da Vila. Com a desativação parcial do Sistema Funicular da Serra Velha, na década de 70, parte dos funcionários foi dispensada ou aposentada e outros foram contratados para cuidar do novo sistema de transposição da serra, construído com tecnologia japonesa e financiado por capital norte-americano. Em 1981, o Sistema Funicular foi totalmente desativado e o transporte de passageiros para Santos, extinto. O desenvolvimento tecnológico impulsionou a mudança de cultura da rede, desconectando alguns atores, conectando outros novos, mudando sua estrutura e dinâmica. A ferrovia, agora modernizada, pode ser administrada à distância sem o 


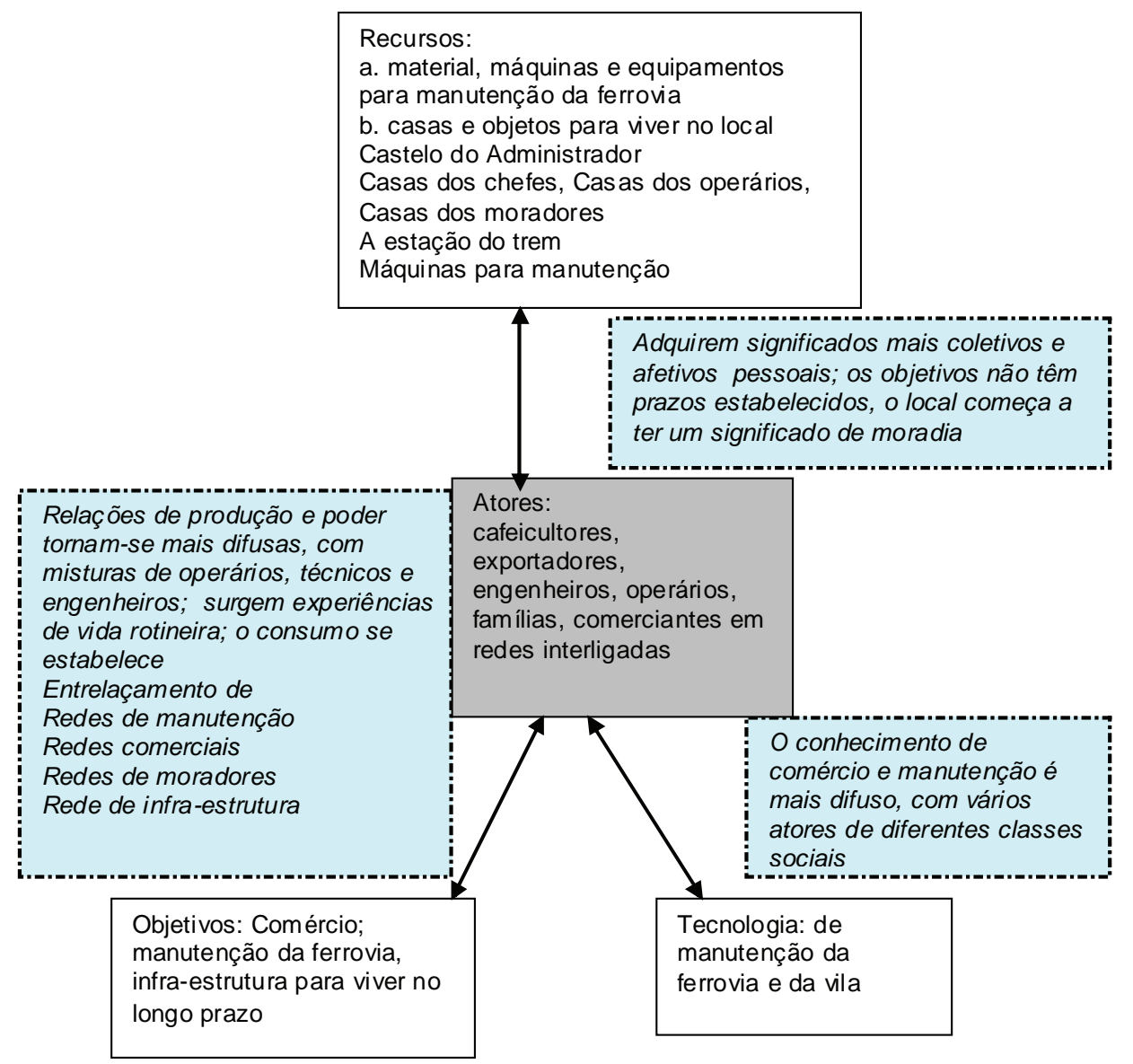

Figura 4. A rede de Paranapiacaba num segundo momento, agora com o objetivo de comércio. Fonte: construção dos autores, 2009.

uso intensivo de mão de obra. A Vila deixa de ser parte integrante do complexo ferroviário tendo que buscar outra identidade.

Esta nova situação, de acentuada transição, origina relações difusas (por exemplo, um técnico desempregado, que é mão de obra especializada, mas não tem lugar de trabalho no local). É uma nova experiência para os atores, que assistem a decadência do local, o envelhecimento e abandono dos objetos.

Dada a dinâmica de uma rede, a partir da década de 1980, surgiram diversos movimentos para preservação do patrimônio histórico e natural da Vila, entendidos por este trabalho como os primeiros passos para a modificação da rede social prevalente. O Castelinho, o clube e o mercado foram restaurados. Em 1986 foi apresentado o Plano de Preservação e Revitalização, e em 1987, Paranapiacaba foi tombada historicamente pelo Condephaat (Conselho de Defesa do Patrimônio Histórico, Artístico, Arqueológico e Turístico do Estado de São Paulo). O tombamento incluiu o núcleo urbano, os equipamentos ferroviários e a área natural que envolve a Vila, mas pouco resultado foi visto. O abandono continuou evidente, mas com o crescimento de uma perspectiva de um novo objetivo a ser desenvolvido.

A maior parte dessas mudanças ocorreu por iniciativas do governo e instituições de fomento, sem a participação da sociedade. Em outros termos, não havia uma rede social que desse suporte ao novo objetivo de uma rede de negócios turísticos. Um documento que torna um local um patrimônio histórico não transforma as pessoas em atores da hospitalidade do dia para a noite nem atrai turistas. Em conseqüência, o abandono continuava.

No ano de 2003 a Prefeitura de Santo André compra a Vila ferroviária e inicia um trabalho efetivo para recuperação e preservação local, alavancando seu desenvolvimento social e econômico. Agora voltado para a auto-sustentação pela atividade turística onde se destacam os seguintes referenciais: Estação do Alto da Serra, Passarela Metálica (de 1899), Igreja de Bom Jesus de 


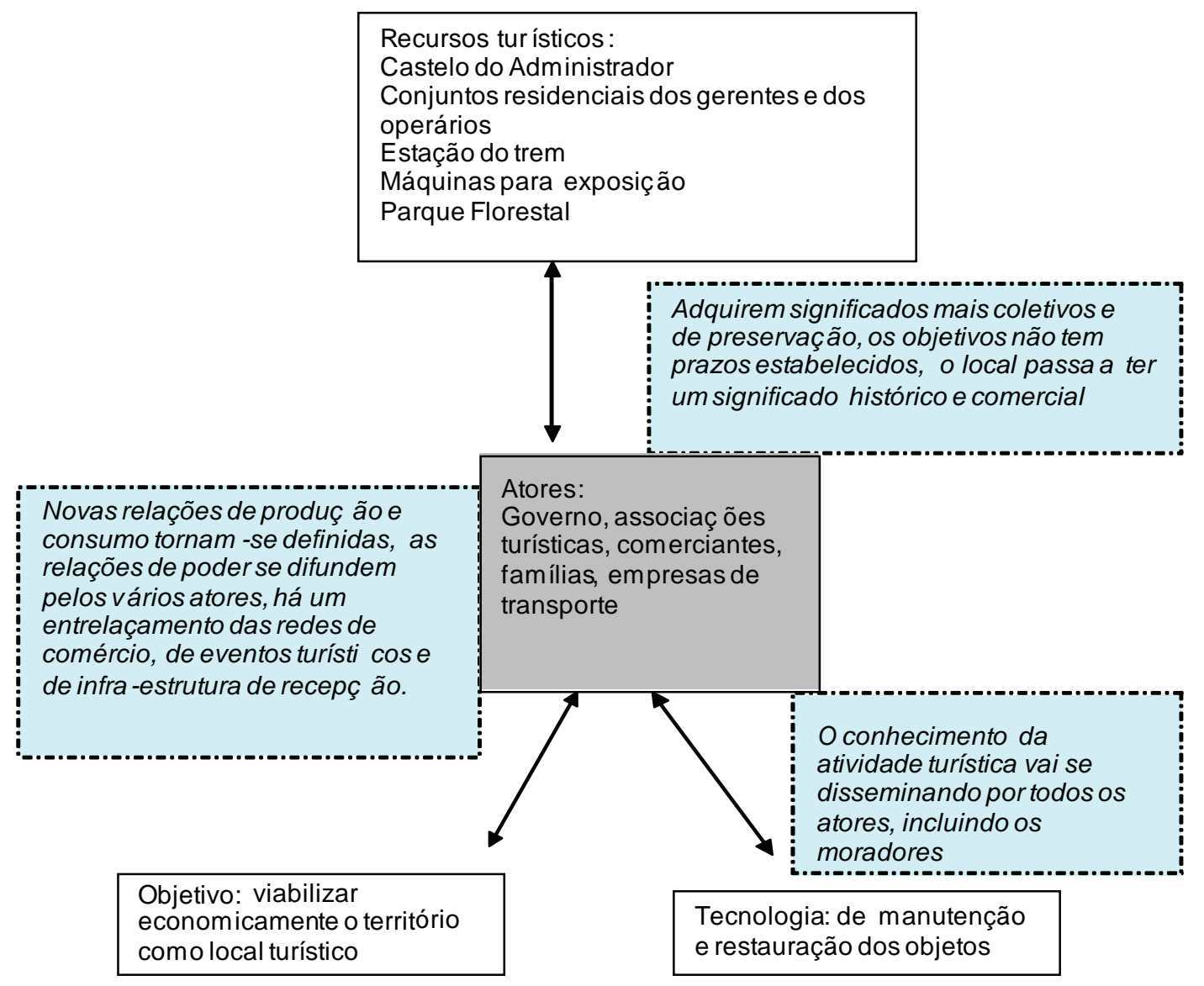

Figura 5. Configuração da rede de Paranapiacaba quando o turismo passou a ser o objetivo. Fonte: construção dos autores, 2009.

Paranapiacaba (de 1889), Castelinho (de 1897), Casa Fox (de 1897), Edifício do Mercado (de 1899), Clube União Lyra Serrano (de 1907). Além destes atrativos o distrito de Paranapiacaba abriga recursos naturais da Mata Atlântica que estão preservados pelo Parque Natural Municipal Nascentes de Paranapiacaba, que é uma Unidade de Conservação, criada em pela Prefeitura de Santo André, com o objetivo de proporcionar a manutenção do equilíbrio do ecossistema para usufruto das gerações atuais e futuras. Documentos da prefeitura buscam ressaltar as qualidades do local.

Por vários motivos Paranapiacaba esteve à frente do País, como, por exemplo, foi o primeiro local a ter iluminação elétrica, saneamento básico, o local onde ocorreu a primeira partida de futebol e o embrião do primeiro sistema previdenciário do país. Por ser a única Vila Ferroviária conservada desde sua fundação no Brasil, pelos motivos apresentados, Paranapiacaba garantiu seu nome na História (Prefeitura de Santo Andrèe, 2008).

Neste último movimento, quando o governo entende que deve haver a participação da sociedade, começa a nascer a rede social que dará suporte à rede turística. Como se percebe, há uma relação entre as características estruturais da rede, os papéis dos atores e os objetivos presentes. A configuração inicial dessa última rede pode ser vista na Figura 5. Agora a tecnologia está a cargo do objetivo de manutenção dos recursos e introduz-se a tecnologia de informação para comunicação e venda dos produtos turísticos.

\section{Culturas da Vila de Paranapiacaba}

O estudo da dinâmica das redes proporciona uma visão das mudanças de relacionamentos entre os nós ao longo do tempo, acompanha a entrada e a saída de atores, recursos e tecnologia, alterando as configurações das relações de poder, cultura e experiência da rede. As condições ambientais de Paranapiacaba passaram por várias configurações espaço-temporal e, portanto, culturais. A primeira ocorreu na implantação da ferrovia 
(1860 a 1867) onde os principais atores eram o governo brasileiro, com interesse em viabilizar as exportações de café, os cafeicultores, os empreendedores da ferrovia (Barão de Mauá, Bancos Ingleses), os cinco mil funcionários e os engenheiros envolvidos na obra, além de todos os outros elementos de apoio a este empreendimento.

Com o término da implantação em 1867 a Vila tornou-se elemento de suporte à operação da ferrovia mudando a constituição e a importância dos atores e, ainda em sua evolução, como pólo tecnológico, assume a frente dos desenvolvimentos do País pela disponibilidade da iluminação, saneamento básico, esportes, eventos culturais e religiosos no clube além de tornar-se o embrião do primeiro sistema previdenciário do Brasil.

Um terceiro período ocorre a partir de 1946, quando a estrada foi encampada pela União que optou pela transferência do sistema funicular para o sistema de cremalheira, envolvendo tecnologia japonesa. Caracteriza-se pela saída do ator empresa e do ator bancos ingleses; substituídos pela parceira do ator governo com os japoneses. A vila continua sendo palco de avanços tecnológicos, com constantes mudanças dos atores, das formas de produção e de consumo. Em contraste com este avanço tecnológico há o declínio das relações sociais locais, uma vez que as novas tecnologias requerem conhecimento especializado e possibilita a administração das operações à distância.

O período atual, a partir de 2003 quando foi adquirida pela Prefeitura de Santo André com o objetivo de proporcionar a manutenção de equilíbrio do ecossistema para usufruto das gerações atuais e futuras, a Vila passou a uma nova configuração de produção, consumo, poder e experiência com a subdivisão em duas redes: a rede ligada à ferrovia e a rede histórico-cultural. A Vila sai de uma ação de apoio e volta-se para uma atividade de preservação e desenvolvimento dos agentes moradores, de uma cultura de preservação e auto-sustentação de seus atores e recursos pelo turismo. Note-se, no entanto, que sua evolução depende fortemente do apoio dos governos municipal, estadual e federal, além de entidades de preservação.

Embora esta análise aponte para datas, estas devem ser entendidas como referência, uma vez que a cultura evolui continuamente sem apresentar marcos temporais bem definidos. Outra observação é que dentro de uma cultura pode-se identificar uma dinâmica da rede que na sua evolução abre espaço para outra rede, seja por pressões externas (grupos de interesse), seja por pressões internas (jogos de poder entre os atores).

Verifica-se, da análise realizada; que o sistema evolui de uma rede de negócios onde os relacionamentos se caracterizam por afinidades produtivas e tecnologias substituíveis para uma relação de complementaridade entre operadores que partilham a formação de um pacote turístico. Evolui também de uma governança centralizada para uma distribuição de influência e poder entre os vários atores. Evolui de uma rede com um negócio principal para vários negócios de pequeno porte, que é característica de um local turístico (Tremblay, 1998). Estas análises sustentam a afirmativa da dinâmica e mudança das redes, em oposição à visão de um ciclo definido.

\section{Natureza da ligação e característica estrutural da rede atual}

A representação das relações entre atores e recursos por um grafo descreve a concepção mental, ou o mapa cognitivo das características relevantes sob a perspectiva dos elementos envolvidos (Bougon, Weich, Buikhorist, 1977; Ford, 2003). A rede é um modelo mental (Lipnack, Stamps, 1994), um mapa da interdependência entre atores, estabelecida pelos relacionamentos, com o objetivo de melhor aproveitamento dos recursos. Os recursos podem ser humanos, ou entradas técnicas que se constituem em um potencial de ação enquanto que as atividades representam o fluxo de serviços que podem resultar dos recursos (Grandori, Soda, 2006). Esta representação pode ser retrospectiva, ou prospectiva. A Figura 6 apresenta um modelo de relacionamento atual entre os atores da Vila durante a realização da pesquisa (Pires, 2006).

As linhas expressam o relacionamento entre atores cujo conteúdo é representado por fluxo. As escolas públicas, no sentido de criar empregabilidade para os jovens da região, trabalham na formação de monitores turísticos, criando assim o relacionamento com os atrativos culturais, atrativos naturais, associação dos receptivos e outros que são influenciados pela ação destes monitores. Neste caso a relação é biunívoca, uma vez que estes atores podem influenciar as escolas, participando-as de suas necessidades.

Os atrativos culturais têm relação com a hospedagem e com a alimentação, uma vez que aqueles se constituem em lugar de divulgação das capacidades da Vila. Olhando sob o ponto de vista de rede, o comércio é elemento divulgador e impulsionador da freqüência aos atrativos, pois atua como elemento de complementação às outras atividades. Todos os elementos se completam, são necessários uns aos outros. Identifica-se a integração vertical no sentido de relacionamentos de recursos complementares que operam em diferentes estágios da cadeia de valor. É também interessante observar que, diferentemente de outros setores como o automo- 


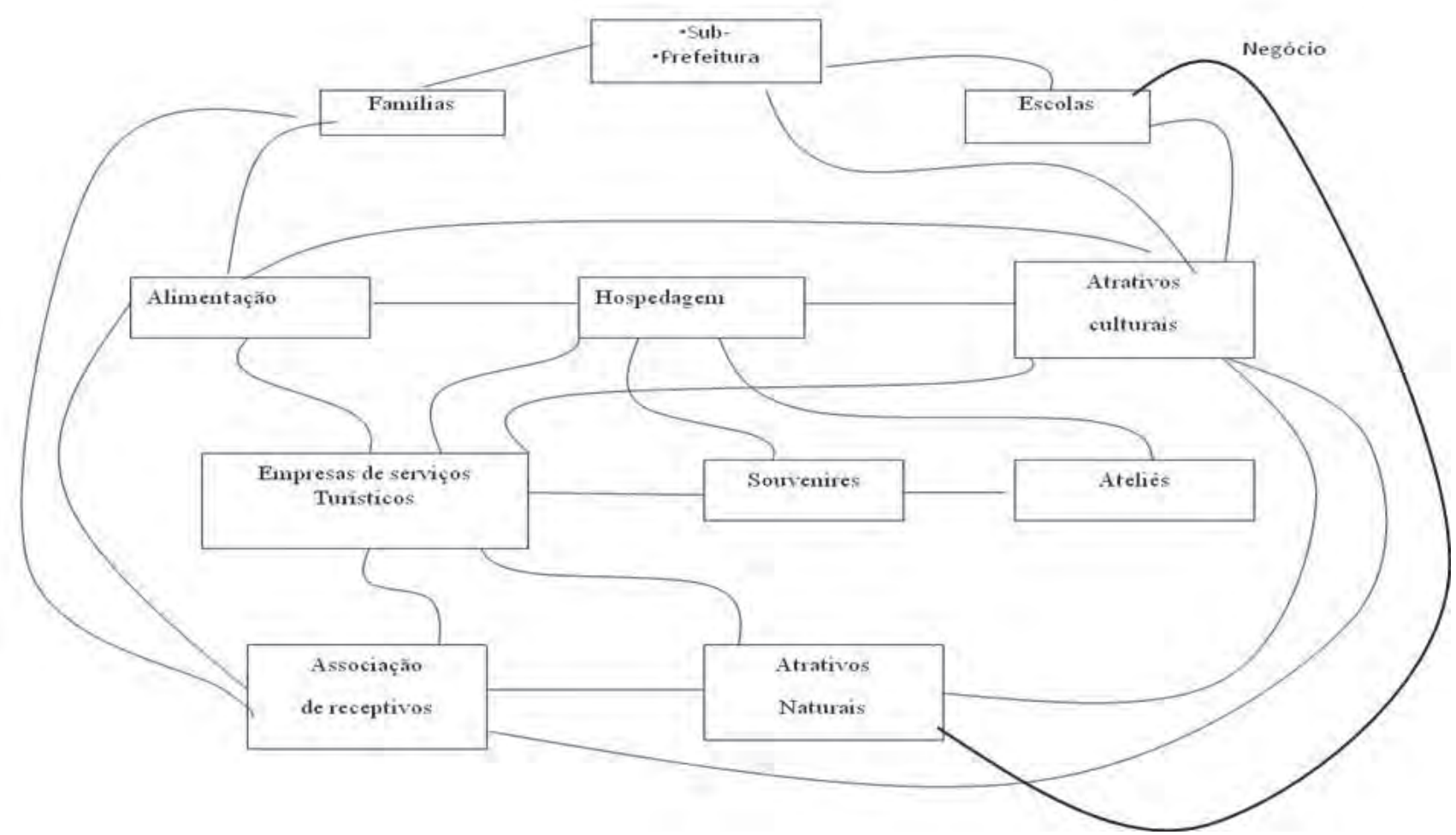

Figura 6. Rede representativa dos recursos e atividades de Paranapiacaba. Fonte: Os autores, adaptado de Pires, 2006.

tivo, a produção no turismo não segue um processo com seqüência rígida sendo que as atividades que compõem um produto turístico não precisam ocupar uma posição rígida na cadeia de valor, podendo ocorrer em qualquer tempo.

Outra característica importante do setor é que são necessárias empresas com produtos aparentemente rivais e, portanto, podem contribuir para um mesmo produto turístico. Na Figura 7 são apresentados alguns laços horizontais que conectam empresas rivais e, por operarem no mesmo estágio da cadeia de valor, ou por oferecerem produtos substitutos para o mesmo mercado, ocorrem entre os restaurantes, hospedagens, ateliês, etc. É interessante observar que esta competição contribui para a atratividade da Vila porque incentiva a competição por preço, além de contribuir para a diversidade e flexibilidade, por exemplo, oferecendo diferentes opções de sabores para diferentes interesses dos clientes e dos dias da semana. Os atrativos naturais e os atrativos culturais competem, mas de forma diferente da rede de negócios.

As ligações verticais e horizontais podem ser formais ou informais. Uma vez que as ligações formais são por contratos registrados em fórum público, a maioria das ligações, representadas nas Figuras 6 e 7 são informais e não ocorrem de forma estrategicamente planejada en- tre as empresas envolvidas. Elas são adequadamente compreendidas no paradigma de redes sociais. Essas relações informais podem ser essenciais como elementos alavancadores de todo o empreendimento turístico, já que atuam integradores de recursos complementares em opções, abrangendo desde pizzarias a restaurantes de peixe, churrascarias, etc., criando flexibilidade e variedade para os clientes. Em termos de rede o laço horizontal não é visto somente do ponto de vista de conflito, mas também de complementaridade. Este é o principal ponto diferenciador de um enfoque de negócio para um enfoque relacional, como o aqui apresentado. Este último enfoque possibilita uma análise muito mais ampla das relações entre empresas e permite até contestar alguns conceitos largamente consolidados de concorrência entre empresas.

Das pesquisas realizadas por Pires (2006) pode-se afirmar que a natureza da ligação entre os atores mostra uma tendência de incremento da intensidade, com crescente adesão dos atores da cidade, principalmente os jovens e estudantes, no desenvolvimento dos papéis de atores do turismo. Foram coletados relatos dos guias e pequenos empresários sobre a consciência que tinham dos seus papéis. Paralelo a esse movimento e interdependente dele, a característica estrutural da rede atual coloca o papel de ator (formas de relações) voltado para 


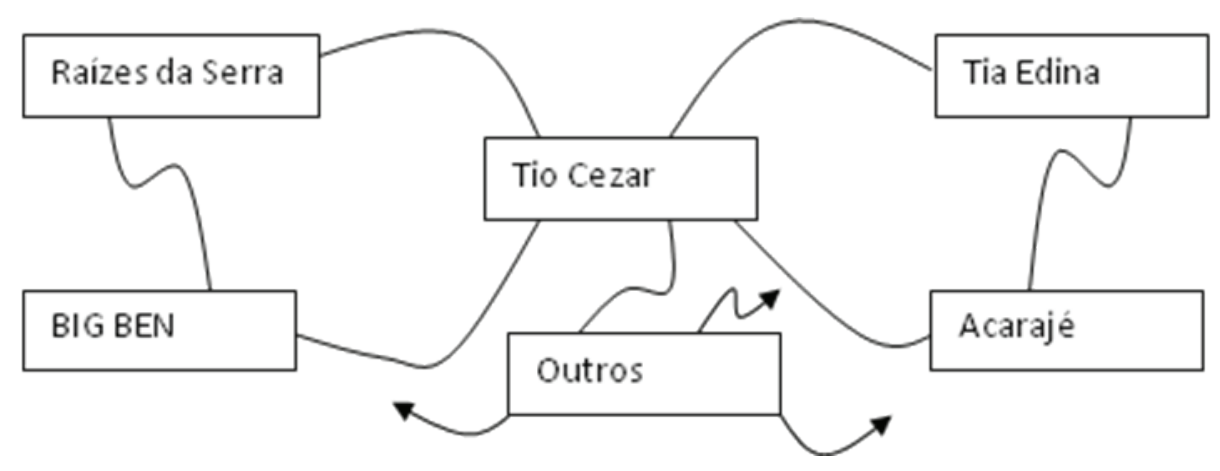

Figura 7. Inter-relação entre os negócios na área de alimentos. Fonte: construção dos autores, 2009.

o turismo (que é o objetivo que ordena as relações), utilizando de maneira específica os recursos (casas, máquinas, etc), como objetos de turismo e não como objetos utilitários.

\section{Modelo Básico para Análise da Dinâmica da Rede}

Unindo-se as contribuições teóricas e as análises sobre o caso apresentado, foi possível propor e sustentar um modelo básico para pesquisas das mudanças culturais em redes. Este trabalho sugere que pesquisas com o objetivo de analisar a dinâmica de uma rede de negócios, a partir dos conceitos de redes sociais, tomem como ponto de partida quatro principais elementos: A. Os atores: B. os recursos que estão disponíveis à rede e a evolução tecnológica que conduz a mudança nos objetivos e na forma de aproveitamento dos recursos; C. As formas de relações entre os atores, incluindo a maneira como utilizam os recursos; D. Os objetivos que guiam todo o sistema de relações. Estes fatores se interconectam em sua evolução dentro do objeto de estudo. O modelo resumido pode ser visto na Figura 8 .

A Figura 8 deve ser vista como uma estrutura de elementos que organizam a rede, nas variáveis expostas anteriormente, ou seja, a dinâmica, o conteúdo transacional, a natureza da ligação e as características estruturais. Assim, por exemplo, as relações de poder dos engenheiros sobre os operários e outros habitantes da Vila são compreensíveis quando se entende que o objetivo era a construção da ferrovia e que os objetos (a tecnologia de construção) exigiam um rígido controle. Quando o objetivo passa a ser o comércio na ferrovia, num segundo momento, a autoridade do engenheiro assume uma nova função, mudando a natureza das transações com os operários, agora objetivando a operação e manutenção da ferrovia, com controles menos rígidos.

Assim, realizando uma análise temporal, com cortes sucessivos no tempo, é possível perceber a evolução da rede, conforme mostraram os vários desenhos. Uma im- portante contribuição metodológica do trabalho foi exatamente mostrar que é possível realizar uma análise dinâmica de uma rede a partir de documentos, entrevistas e reconstrução histórica, substituindo em parte a técnica de acompanhamento. O trabalho se configura inédito, já que não encontramos similar na literatura brasileira.

\section{Conclusões}

O objetivo deste artigo foi desenvolver uma análise de rede de negócios a partir da afirmativa de que as relações e a rede se transformam no tempo. A partir da análise do caso, a resposta obtida é que a afirmativa se mantém, ou seja, há evolução das redes causadas por mudanças nos relacionamentos entre atores, recursos e objetos.

Alguns autores (Larson, 1992) têm defendido a hipótese de que redes são como produtos, que têm um ciclo de vida e morrem. No entanto, ao considerar um conceito de rede de negócios a partir do paradigma de rede social (Castells, 2000), pode-se afirmar que a rede se transforma no tempo, tanto em sua estrutura, quanto em sua dinâmica, sendo desnecessário teórica e metodologicamente seguir a idéia de ciclo de vida. A aceitação dos ciclos tem levado os pesquisadores a analisarem diacronicamente uma rede e concluírem sobre o estágio em que ela se encontra, ou, no máximo, com uma comparação entre um momento anterior e o presente. Uma análise histórica, conforme nossa proposta, busca as mudanças da rede a partir de quatro fatores estruturantes - os atores, os recursos, a evolução tecnológica e os objetivos, cuja interligação pode ser vista na Figura

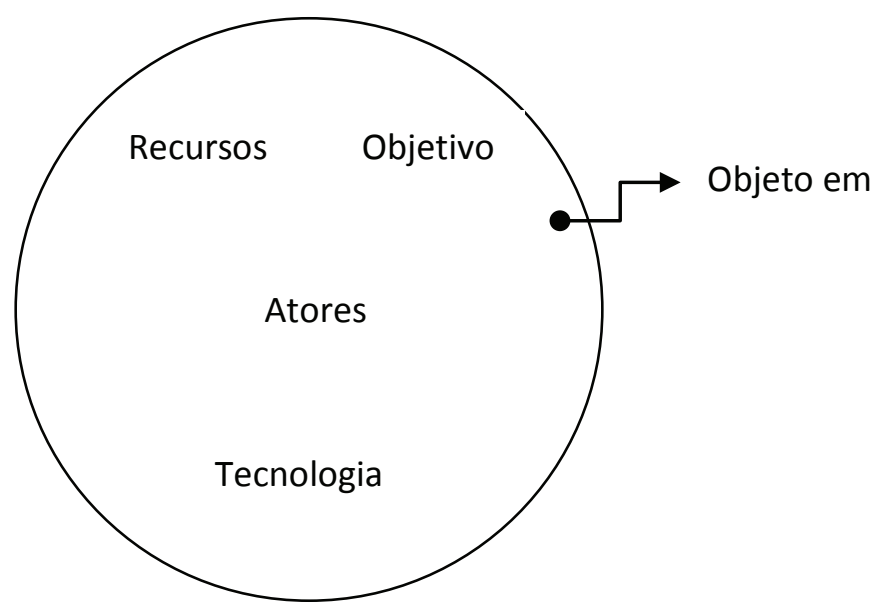

Figura 8. Modelo teórico resumido para a dinâmica das redes. Fonte: Construção dos autores, 2009. 
2. Os fatores se ordenam num amplo espectro de variáveis, tais como as citadas por Tichy (1979) e organizadas por Castells (2000), classificadas em quatro fatores a saber: A. A dinâmica da rede, entendendo-se como as formas de relações entre os atores; B. Os conteúdos transacionais, entendendo-se como o fluxo da rede, no uso de objetos, C. A natureza da ligação, entendendose como intensidades, freqüências, confiança e outras medidas das relações, D. As características estruturais da rede, entendendo-se como o tamanho, existência de centralidade, de governança.

A partir do modelo da Figura 2 e baseado nos princípios do sistemismo, que considera relações causais bidirecionais e que busca a transformação das relações, desenvolveu-se um raciocínio sobre as várias estruturas e dinâmicas de redes que se sucederam no lugar conhecido como Vila de Paranapiacaba.

A triangulação de dados a partir de documentos históricos, observações no local e entrevistas mostrou-se adequada para fornecer dados sobre os movimentos da rede. Os resultados apontaram que a Vila passou por três estágios de configurações, com estruturas diferentes de redes, com atores que foram se modificando (ou sendo substituídos, ou realizando outras funções), com recursos que tiveram seus destinos alternados (máquinas e edificações que deveriam funcionar e hoje são para olhar) e objetivos que se transformaram (de construir a ferrovia, para o objetivo de comercializar, e atualmente para o objetivo de realizar turismo).

A Vila é um caso único, pois nasceu de um projeto político e comercial, tornou-se uma rede de construção durante alguns anos, mudou sua estrutura para atender aos objetivos comerciais após o término da construção, teve seu auge e declínio, estagnou, isto é, ficou algum tempo sem objetivo definido, por isso seus atores estavam com fluxos e atividades indefinidas, até que a Prefeitura de Santo André colocou o novo objetivo de destino turístico, reordenando as estruturas e dinâmica dos atores.

A afirmativa de transformação da rede e o esquema conceitual proposto abrem campos interessantes de pesquisas, numa corrente diferente das análises econômicas de redes, que com uma certa rigidez concluem sobre a capacidade competitiva da mesma e sobre seu ciclo de vida, tal como se analisam os ciclos de negócios e de cidades como Americana, no interior do Estado de São Paulo, com sua tecelagem e Franca, também no interior de São Paulo, com o negócio de calçados.

Concluímos que o caso analisado mostrou ser possível defender a tese do fluxo das redes, diferente da tese do ciclo de vida. Outras cidades que têm se transformado no tempo, tais como Parati, no Rio de Janeiro, que tem se tornado centro cultural e São Luiz, no Maranhão, que tenta ser um centro empresarial, poderiam ser analisadas na mesma perspectiva.

\section{Referências}

Borgatti, S. and Everett, M.

2006 "A Graph-theoretic perspective on centrality". Social Network, 28: 466-484.

Bougon, M.; Weich,K. and Buikhorist, D.

1977 "Cognitions in organizations: An analysis of the Utrecht Orchestra”. Administrative Quarterly, 22: 606-639.

Caporali, R. and Volker, P. (Org)

2004 "Metodologia de Desenvolvimento de Arranjos produtivos Locais". Projeto Promos-Sebrae, Versão 2.0, SEBRAE, Brasília.

Castells, M.

2000 "Material for an exploratory theory of the network society”. British Journal of Sociology, 51: 1: January/ March: 5-24.

1999 A sociedade em rede, v.1. São Paulo: Paz e terra.

Ford, D.; Gadde, L.; Hakansson, H. and Snehota, I.

2003 Managing Business Relationships. Chichester: John Wiley.

Gemser, G., Leenders, M.A. and Wijnberg, N.

1966 "The dynamic of inter-firm network in the course of Industry life cicle: The role of appropriability". Technology Analysis \& Strategic Management, 8: 4: 439-453.

Giglio, E. and Kwasnicka, E.

2005 "O lugar do consumidor nos textos sobre rede". XXIX Congresso EnAnpad, ANPAD, Brasília.

Grandori, A. and Soda, G.

1995 "Inter-firm networks: Antecedents, mechanisms and forms". Organization Studies, 16: 2: 183-214.

2006 "A relational approach to organization design". Industry and Innovation, 13: 2: jun: 151-172.

Hakansson, H. and Snehota, I.

1995 Developing Relationships in Business Networks. London: T.J. Press.

Halinen, A. and Tahtinen, J.

2002 "A process theory of relationship ending". International Journal of Service Industry Management, 13: 2: $163-180$.

Halinen, A. and Tornroos, J.

2005 "Using case methods in the study of contemporary business networks". Journal of Business Research, 58: 9: sept: 1285-1297.

Larson, A.

1992 "Network dyads in entrepreneurial settings: A study of the governance of exchange relationships". Ad- 
ministrative Science Quarterly, 37: 1: mar: 76-105.

Lastres, H. and Cassiolato, J.

2007 "Mobilizando conhecimento para Desenvolver Arranjos e Sistemas Produtivos e Inovativos Locais de Micro e Pequenas Empresas no Brasil: Disponível em http://redesist.ie.ufrj.br/glossario.php, acesso em 12/06/2007.

Lipnack, J. and Stamps, J.

1994 The age of the network: Organizing Principles for the 21 st Century. New York: John Wiley \& Sons.

Maturana, H. and Varela, F.

1987 The tree of knowledge. Boston: Shambhala.

Morin, E.

1991 Introdução ao Pensamento Complexo. Lisboa: Instituto Piaget.

Mouzas, S.; Henneberg, S. and Naudé, P.

2007 "Developing network inside". Industrial Marketing Management, 37: 2: Apr: 167-180.

Pires, G.

2006 Análise de oportunidades de negócios turísticos no distrito de Paranapiacaba. (Dissertação). Mestrado. Universidade Paulista - UNIP, São Paulo.

Porter, M.

1998 "Clusters and the new economics of competition". Harvard Business Review, 76: nov-dez: 77-90.

Prefeitura de Santo André.

2008 "Paranapiacaba, Breve Histórico". Disponível em $<$ http://www.santoandre.sp.gov.br/bn_conteudo. asp?cod=482 >. Acesso em 10 março, 2008.

Sebrae SP.

2003 "Termo de referencia para Atuação do Sistema SEBRAE em Arranjos produtivos locais".

Publicação SEBRAE.

Tichy, N.; Tushman, M. and Fombrun, C.

1979 "Social Network Analysis for Organizations". Academy of Management Review, 4: 4: 507-519.

Tremblay, P.

1998 "The economic organization of tourism". Annals of Tourism Research, 25: 4, Oct: 837-859.

Vale, G.

2004 "Empreendedores coletivos em redes organizacionais: novos agentes gerando um padrão diferenciado de competitividade". XXVIII Congresso EnAnpad, ANPAD, Curitiba.
Recibido: 